\title{
Large impacted pancreatic stone removed with single-operator pancreatoscopy and electrohydraulic
}

\section{lithotripsy}

\author{
Chang-II Kwon, MD, Stuart Sherman, MD
}

A 59-year-old man had chronic calcific pancreatitis secondary to alcohol and smoking. He had acute flares of pain and elevation of serum pancreatic enzymes. A CT scan revealed features of chronic pancreatitis, including large pancreatic duct calculi in the dilated main duct. On previous ERCP examination 2 months prior, removal of a $15-\mathrm{mm}$ impacted pancreatic stone near the genu was not attempted because of its large size and a relatively narrow downstream duct. After a failed attempt to advance a 3-4-5F catheter dilator beyond the stone, a 5F Soehendra stent retriever (Cook Medical, Winston-Salem, NC) was advanced into the pancreatic duct upstream to the stone, and a pancreatic duct stent was placed. In the current ERCP examination, the main pancreatic duct contained a large impacted stone in the upper head (Fig. 1). After dilation adjacent to the impacted stone with a 4-5-7F catheter dilator and a 6-mm balloon dilator, the ventral pancreatic duct was explored endoscopically by use of Spyglass (Boston Scientific, Natick, Mass). The impacted pancreatic duct stone was identified. Electrohydraulic lithotripsy was successful for achieving more than $50 \%$ fragmentation of the impacted stone and successful removal of the fragments with a stone retrieval balloon (Video 1, available online at www.giejournal.org). Two stones in the body of the pancreas in the lower branch of a bifid duct were not treated.

Disclosure

All authors disclosed no financial relationships relevant to this publication.

This is the author's manuscript of the article published in final edited form as:

Kwon, C.-I., \& Sherman, S. (2015). Large impacted pancreatic stone removed with single-operator pancreatoscopy and electrohydraulic lithotripsy. Gastrointestinal Endoscopy, 82(2), 406.

http://doi.org/10.1016/i.gie.2015.03.1970 
Figure 1. Endoscopic retrograde pancreatographic view of impacted pancreatic duct stone (arrow) near the genu of the pancreas.

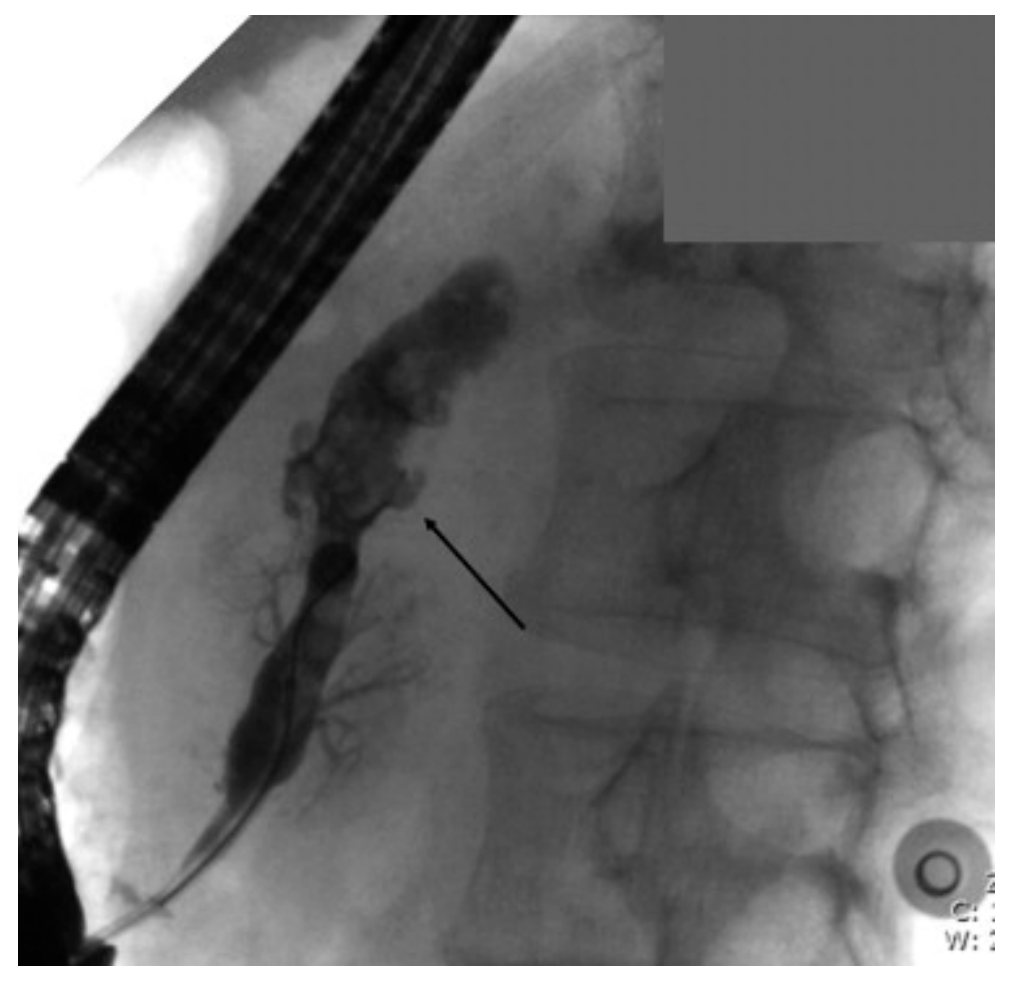

